\title{
Overcoming the Challenge of Cooperating with Competitors: Critical Success Factors of Interorganizational Systems Implementation
}

\author{
Nitza Geri \\ The Open University of Israel \\ Raanana, Israel \\ nitzage@openu.ac.il
}

\begin{abstract}
The growing phenomenon of competitors that use a common interorganizational system (IOS) raises challenging strategic and organizational issues. Sometimes organizations join IOS initiatives although it seems to weaken their competitive position. This paper analyzes, in retrospect, the fully automated Tel-Aviv Continuous Trading system (TACT) implemented by the Tel-Aviv Stock Exchange (TASE) and its members, about a decade after its inauguration. It examines TACT's organizational feasibility and its critical success factors, using the Theory of Constraints (TOC) as a theoretical basis. The paper provides a comprehensive analysis of one system, including the point of view of both the initiator (TASE) and the participants (TASE members). TACT's implementation complexity was further escalated since all users had to convert to it simultaneously. Therefore, intensive cooperation was required, especially between Israel's five largest banks, which had seemingly faced a value paradox of IOS, since TACT was supposed to undermine their competitive position by reducing customer lock-in. This study contributes to the informing science transdiscipline by extending its applicability to interorganizational contexts, and by introducing the Theory of Constraints as an effective analysis tool that can be integrated within the informing science framework. It emphasizes the importance of a neutral managing intermediary, provides guidelines for successful IOS implementation, and suggests that the main critical success factor is information systems management skills.
\end{abstract}

Keywords: Interorganizational system (IOS), information systems adoption, information systems implementation, organizational feasibility, strategic value, electronic stock exchange, Theory of Constraints (TOC).

\section{Introduction}

Material published as part of this publication, either on-line or in print, is copyrighted by the Informing Science Institute. Permission to make digital or paper copy of part or all of these works for personal or classroom use is granted without fee provided that the copies are not made or distributed for profit or commercial advantage AND that copies 1) bear this notice in full and 2) give the full citation on the first page. It is permissible to abstract these works so long as credit is given. To copy in all other cases or to republish or to post on a server or to redistribute to lists requires specific permission and payment of a fee. Contact Publisher@InformingScience.org to request redistribution permission.
"TACT has changed the rules of the game and the real beneficiaries are the customers, i.e., the investors".

(A CEO of a major Israeli

investment house)

The increasing phenomenon of competitors that collaborate and use a common interorganizational information system (IOS), such as Covisint in the automotive industry (Willcocks \& Plant, 2003), 
or ORBITZ in the airline industry (Granados, Gupta, \& Kauffman, 2007), evokes challenging strategic and organizational issues. Practically, it may be more efficient that all participants in a certain industry share a common system and increase the benefits of network externalities (Shapiro \& Varian, 1999; Zhu, Kraemer, Gurbaxani, \& Xu, 2006). However, from a strategic perspective, there can be a value paradox of IOS: organizations join IOS initiatives although it seems to weaken their competitive position (Borman, 2006). One possible explanation is that they may be compelled to do so by powerful initiators, e.g., an influential retailer requires its suppliers to adopt a certain system. Previous studies have found that external pressure by trading partners enhanced IOS implementation (Chwelos, Benbasat, \& Dexter, 2001; Hart \& Saunders, 1997, 1998; Premkumar, Ramamurthy, \& Crum, 1997; Teo, Wei, \& Benbasat, 2003). However, this may not explain a situation where major competitors collaborate in a joint IOS initiative. The organizational challenge of an IOS manager is to resolve conflicts among the participating organizations in order to establish a successful IOS.

This study examines two major research questions: why organizations initiate or join IOS and how competing organizations overcome the challenges of participating in a common IOS. The term IOS implementation as used in this paper encompasses both the initial adoption and the mode of continued use of IOS. Although IOS implementation concerns have been widely researched (Chwelos et al., 2001; Teo et al., 2003), studies like Granados et al. (2007) that examine the implementation of the same IOS by competing organizations are rare.

Geri \& Ahituv (2008) have developed a model of IOS feasibility that is based on the Theory of Constraints (TOC) (Goldratt \& Cox, 1986; Gupta, 2003; Mabin \& Balderstone, 2000; Ronen, 2005; Ronen \& Pass, 2007). Geri \& Ahituv's (2008) model aims to explain the overall IOS implementation level in an organization. It relates to all the potential IOS connections of an organization with its business customers, suppliers, competitors, business partners, banks and others. That model has been empirically supported in a field survey of 139 organizations. The earlier research focused on the organization level, whereas this study concentrates on the system level, particularly an IOS that is shared, or is intended to be shared, by competitors.

This paper extends the IOS feasibility model of Geri \& Ahituv (2008) and analyzes, in retrospect, the implementation of the fully automated Tel-Aviv Continuous Trading system (TACT) by the Tel-Aviv Stock Exchange (TASE) and its members, about a decade after its inauguration. It provides a comprehensive analysis of one system, which includes the points of view of the initiator (TASE) as well as the participants (TASE members), and examines TACT's feasibility and its critical success factors. Structured interviews were conducted with TASE managers and member organizations managers involved in the initiation, development, implementation, operation, and control of TACT. Additionally, a mail survey was sent to all 31 TASE members including all Israeli large and medium size banks, and 20 replies were received (64.5\% response rate).

TACT was chosen as the research object for the following reasons: Financial services are ebusiness management pioneers and provide leading examples of IOS applications and patterns that may evolve in other industries (Gordon, 2002; Wise \& Morrison, 2000). TACT is a strategic information system that has fundamentally changed the industry business processes. TACT's implementation complexity was further escalated since all the members had to convert to the new trading system simultaneously. Therefore, intensive cooperation and coordination were required between all members, especially between Israel's five largest banks. Moreover, these banks seemingly faced a value paradox of IOS, since TACT was supposed to undermine their competitive position and increase customers' bargaining power by reducing customer lock-in (Shapiro \& Varian, 1999).

This research contributes to the informing science transdiscipline (Cohen, 1999, 2009; Gill \& Bhattacherjee, 2007) by extending its applicability to interorganizational contexts. It introduces 
the Theory of Constraints (Goldratt \& Cox, 1986) as an effective analysis tool, which can be integrated within the informing science framework (Gill \& Cohen, 2009). The study emphasizes the importance of a neutral intermediary that manages the IOS project, as well as its ongoing operation. The paper provides guidelines for successful implementation of IOS and suggests actions, which may increase their value. Following Mata, Fuerst, \& Barney (1995), it proposes that the main critical success factor is information systems management skills.

The next section presents the theoretical background, which includes an overview of the Theory of Constraints and the extended IOS feasibility model. It is followed by a methodology section that explains how the data was collected and validated. Then, TASE and the main phases of TACT's development and implementation are described. The next three sections analyze the TACT implementation: the first one examines TACT's initiation through the perspective of the extended IOS feasibility model. The second section deals with overcoming the organizational challenges that were identified as the major constraint of the implementation. The third section examines TACT in retrospect, how it influenced the market and its members. The paper ends with discussion of the theoretical and practical implications of the study, as well as limitations and suggestions for further research, and conclusions.

\section{Theoretical Background and the Research Model}

\section{The Theory of Constraints}

The strength of a system is measured by its weakest link, which in the Theory of Constraints terms is defined as the system's constraint. According to TOC, the attention of management should be focused on the few constraints that prevent the organization from achieving its goal. TOC was initially developed by Eli Goldratt in the mid-1980's (Goldratt \& Cox, 1986) and since then its application has provided thousands of organizations worldwide with significant performance improvements, such as increased throughput, reduced inventory levels and shorter lead time (Mabin \& Balderstone, 2000). Goldratt (1991) initially defined the five focusing steps of TOC for maximizing the performance of a system (see steps 3-7 below). Ronen and Spector (1992) enhanced the process by adding two preliminary steps (see steps 1-2 below). These two steps are essential in situations of dynamic constraints when the binding constraint changes over time (Ronen, Lieber, \& Geri, 2007; Rosolio, Ronen, \& Geri, 2008). Hence, the seven focusing steps are (Ronen, Coman, \& Schragenheim, 2001):

1. Define the system's goal.

2. Determine global performance measures.

3. Identify the system's constraints.

4. Decide how to exploit the system's constraint.

5. Subordinate the system to the constraint.

6. Elevate the system's constraint.

7. If, a constraint has been broken in the previous steps, go back to step 3. Do not let inertia become the system's constraint.

TOC has been successfully implemented by manufacturing organizations, mainly in the aerospace, apparel, automotive, electronics, furniture, semiconductor, steel and heavy engineering industries (Mabin \& Balderstone, 2003), and oil refining (Rosolio et al., 2008), as well as in diverse non-manufacturing sectors, such as health services (Ronen, Pliskin, \& Pass, 2006), financial services (Geri \& Ronen, 2005), the public sector (Shoemaker \& Reid, 2005) and education (Goldratt \& Weiss, 2005). TOC has also been used to enhance effective enterprise software im- 
plementation (Ioannou \& Papadoyiannis, 2004). In this study, we extend the work of Geri \& Ahituv (2008), who used TOC to identify the constraints that limit IOS implementation, and examine this issue in the context of IOS that are shared by competitors who need to cooperate.

\section{The Extended IOS Feasibility Model}

Grounded on TOC, Geri \& Ahituv (2008) have developed a model of IOS feasibility, which explains differences in IOS usage among firms, and empirically tested it using a field survey of 139 medium and large Israeli business organizations. According to the IOS implementation status model suggested by Geri \& Ahituv (2008), IOS implementation level in a certain organization depends on five factors: the perceived potential strategic benefits of IOS, the power position of the initiator, maximal infeasibility, the organization size, and the industry IOS status. This study suggests the extended IOS feasibility model, presented in Figure 1, which adds the notion of interaction characteristics to the factors that affect IOS implementation. The following sub-sections explain each of the model factors, and expand the Geri \& Ahituv (2008) study by emphasizing the implications of IOS that are shared by competitors.

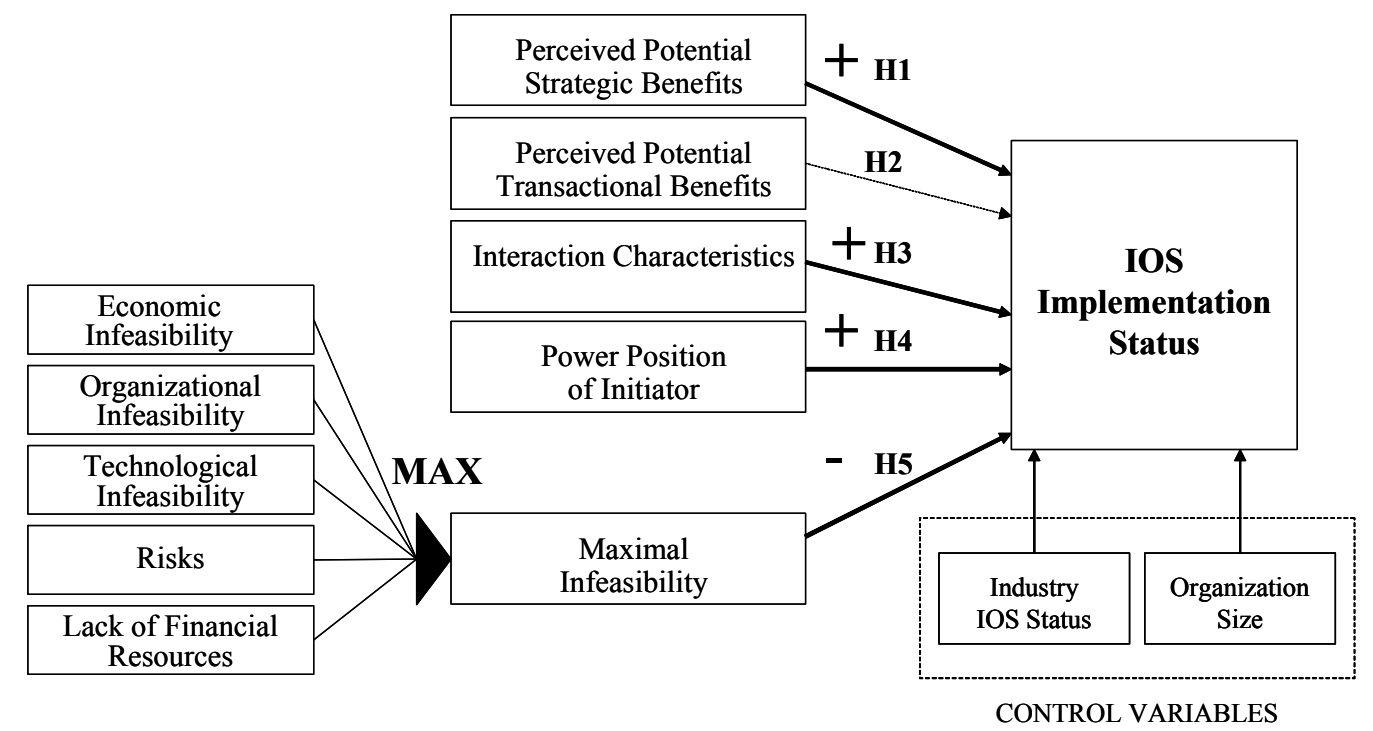

Figure 1: The extended IOS feasibility model

The goal of a business organization is to increase shareholder value. The premise of this study is that IOS utilization assists organizations in achieving this goal. Therefore, the appropriate performance measure should be the IOS implementation status, which is the dependent variable of the extended IOS feasibility model. The model deals with the third stage of TOC and identifies the system's constraints.

\section{Perceived Potential Benefits of IOS}

From a TOC perspective, IOS implementation is just one option among many others for an organization to create value. However, since its resources are limited, the organization will focus on the options that are supposed to add the greatest value. Hence, higher perceived potential benefits of IOS should lead to higher levels of IOS implementation.

Geri \& Ahituv (2008) distinguish between transactional benefits, which relate to operational efficiency, e.g., saving communications costs, improving productivity, or shortening lead times, and 
strategic benefits, which include enhancing or creating a competitive advantage, avoiding a competitive disadvantage, and improvements related to customers, such as better service. As the findings of Geri \& Ahituv (2008) suggest, only the perceived potential strategic benefits of IOS increase IOS implementation, whereas perceived potential transactional benefits have no such influence.

When an IOS is shared by competitors, the transactional benefits should be similar for all participants, although bigger organizations may have a greater potential to reduce costs and improve efficiency. Since the competing organizations use the same IOS, apparently, it may not provide a single participant with competitive advantage, and it probably helps all participants to avoid a competitive disadvantage. However, each participant may have different levels of IOS integration with its internal information system, as well as unique internal work processes that may create competitive advantage.

H1: Perceived potential strategic benefits of IOS positively affect IOS implementation.

$\mathrm{H} 2$ : Perceived potential transactional benefits of IOS do not affect IOS implementation.

\section{Interaction Characteristics}

This study extends the IOS feasibility model of Geri \& Ahituv (2008) and suggests that the characteristics of the interactions between potential partners should be examined in order to determine whether a certain type of transaction might be performed through an IOS. Following transaction cost economics (TCE) (Coase, 1937, 1991; Williamson, 1979, 1996; Williamson \& Winter, 1993), this study suggests that performing a transaction through an IOS is similar to choosing the market (that is, outsourcing in contemporary terms) as the appropriate mechanism for performing a certain type of transaction. Whereas using other means of communication for transferring the relevant information is equivalent to hierarchy (or insourcing in current terminology). This study proposes four major interaction characteristics--frequency, lead-time, structural complexity (Gill, 2008; Gill \& Hicks, 2006), and relationships intensity--that influence the potential to carry out successfully the transactions between trading partners through an IOS.

Frequency, as in TCE (Williamson, 1979), refers to the number of times an organization seeks to initiate a transaction. However, unlike TCE - which recommends market governance for infrequent occasional transactions (i.e., using an IOS, in the context of this study) - the profitability of an IOS grows as the number of transactions increases; it might not be worthwhile to establish an IOS connection between two partners just for a few sporadic transactions.

As the transaction lead-time is shorter, closer coordination is required between the trading partners. An IOS is expected to improve coordination (reduce mistakes, monitoring, adjusting to changing requirements) and decrease uncertainty.

Structural complexity has been defined by Gill (2008) as one of the major constructs of the Informing Science framework (Cohen, 1999; Gill \& Cohen, 2009). Structural complexity refers to the ability to program the transactions (e.g., ordering products that have standard specifications and are identified by a catalog number), as well as to the ability of the trading partners to clearly define all the relevant aspects of the transaction. This notion is similar to both asset specificity and bounded rationality in TCE terms. According to TCE (Williamson, 1979), non-specific transactions should be carried out by the market (i.e., through an IOS). Bounded rationality (Simon, 1957,1971 ) limits the ability to use the market mechanism for performing complex tasks.

Therefore, tasks that have low structural complexity are prime candidates for IOS. In the case of tasks that have high structural complexity, it will be hard to perform all aspects of the transaction through an IOS, but sometimes an IOS that enables information sharing may support such complex tasks. 
Relationships intensity measures the reciprocal dependence of potential IOS partners and relates to the level of required cooperation (e.g., need for data sharing, service availability, customer support). For instance, airlines usually have high relationships intensity with their competitors for various reasons, such as customers that use connecting flights of different carriers.

H3: Suitable interaction characteristics positively influence IOS implementation.

\section{Power Position of an Initiator}

IOS require coordination between independent organizations that do not govern each other and therefore they may be more difficult to implement than information systems that are within the governance of one organization. According to social choice researchers (Arrow, 1963; Mnookin \& Ross, 1995) the only analytic solution for a group decision is dictatorship, and this implies that an IOS requires a strong intermediary that will manage the system. Previous research has found that external pressure of trading partners enhanced IOS implementation (Chwelos et al., 2001; Hart \& Saunders, 1997, 1998; Premkumar et al., 1997; Teo et al., 2003). Furthermore, Geri and Ahituv (2008) have found that $84 \%$ of the 57 organizations in their sample that had not implemented IOS reported that they were not compelled by others to join an IOS. From a TOC point of view, an external pressure of a powerful initiator, such as an important customer, may enhance IOS implementation and force the organization to overcome, at least partially, other implementation barriers.

Sometimes, especially in the context of IOS that are shared by competitors, joining an IOS is apparently against the best interests of an organization because it improves the bargaining power of its trading partners or increases the threat of existing and potential competitors. A neutral intermediary may protect the participants from opportunistic behavior (Williamson, 1996) of the other partners.

H4: A power position of an initiator positively influences IOS Implementation.

\section{Maximal Infeasibility}

The feasibility of an information system is the ability to implement and use it successfully (Ahituv, Neumann, \& Riley, 1994). The three main aspects of feasibility are economic, organizational, and technological. Prior research has measured separately the impact of these and other constructs on IOS implementation (Chwelos et al. 2001). Geri \& Ahituv (2008) have taken a novel approach and, based on TOC principles, defined a new construct: maximal infeasibility, which negatively influences IOS implementation. Maximal infeasibility is defined as the highest among the values of five factors: economic infeasibility, organizational infeasibility, technological infeasibility, risks, and lack of financial resources. The highest value is selected because even if only one of the feasibility requirements is not fulfilled, it will impede IOS implementation. The constraint that inhibits the implementation of IOS depends on the special circumstances of each organization and it determines its ability to implement IOS. The findings of Geri \& Ahituv (2008) suggest that organizational infeasibility is the main barrier to IOS adoption. Nevertheless, in some organizations they surveyed, one of the other four infeasibility aspects was identified as the critical constraint.

In the context of IOS that require the cooperation of competitors, organizational infeasibility may include inability to coordinate with the competitors. Technological infeasibility may be reflected by incompatible information systems infrastructure. Risks may refer to opportunistic behavior (Williamson, 1979, 1996) of the other IOS potential members. Economic infeasibility means that the expected costs outweigh the expected benefits. Sometimes, the organization lacks the required financial resources. One should bear in mind that once the critical constraint (e.g., organizational 
infeasibility) has been resolved, or reduced, one of the other infeasibility elements might become the critical constraint.

H5: Maximal infeasibility negatively influences IOS Implementation.

\section{Control Variables}

The model was controlled by two factors that in previous studies were found to increase IOS implementation: Organization size and Industry IOS status.

Organization size. Larger organizations are considered more capable of adopting innovations (Damanpour, 1991). Nevertheless, empirical results with this regard have been inconsistent, and a meta-analysis of 54 correlations, conducted by Lee and Xia (2006), suggests that although positive relationships generally existed between organization size and innovation adoption, it was moderated by type of information technology innovation, type of organization, stage of adoption, scope of size, and type of size measure. Firm size has significantly influenced IOS adoption (Premkumar et al., 1997; Wang, Chang, \& Heng, 2004; Zhu, Kraemer, \& Xu, 2003). However, sometimes even small organizations may be able to adopt an IOS that was developed by a larger organization or to share high development costs with other organizations.

Industry IOS status. In certain industries, like banking or airlines, IOS are considered a strategic necessity, whereas in other industries their feasibility may be limited due to various reasons. Institutional isomorphism (DiMaggio \& Powell, 1983), which studies the reasons for organizations' similarity, may explain the impact of an industry IOS implementation level on the IOS implementation status of an organization within that specific industry. Prior research (Chwelos et al., 2001; Crook \& Kumar, 1998) has found that higher levels of industry employment of IOS increased the pressure to adopt IOS. The pressures to use an IOS that is shared by competitors may be stronger, since sometimes an organization that does not use the common system may be at a disadvantage due to network externalities (Shapiro \& Varian, 1999).

\section{Methodology}

The main research questions of this study are why organizations initiate or join IOS and how competing organizations overcome the challenges of participating in a common IOS. The IOS feasibility model of Geri \& Ahituv (2008) has been supported at the organization level through a field survey of 139 business organizations. This study focuses on the system level and examines the extended IOS feasibility model in the context of one system from the perspectives of both the initiator and the IOS participants.

The longitudinal case study analyzes the implementation of the fully automated Tel-Aviv Continuous Trading system (TACT) by the Tel-Aviv Stock Exchange (TASE) and its members, and covers the period since its initiation during 1993-1994, through its successful implementation during 1997-1999, and its current operation up to 2008.

\section{Data Collection and the Analysis Process}

The primary data for the analysis was collected during 2000-2001 and included:

- Five structured interviews with senior business managers of TASE and a representative sample of its major members who were involved in the implementation of TACT. All the managers who were asked to be interviewed agreed to participate in the study.

- Five structured interviews with the Chief Information Officer (CIO) (or managers holding similar positions) of TASE members who have been responsible for TACT's implementation 
in their organization. Out of nine managers, five agreed to be interviewed (55\% response rate).

- A mail survey of the top business executives of TASE members that were in charge of stock exchange trade at the time of the survey. The questionnaires were sent to all 31 relevant members (during the years there were many changes in TASE membership), and the 20 received answers represent $64.5 \%$ response rate.

In addition, throughout the years 1997-2008 information about TASE and TACT was gathered from public sources, such as the TASE website (http://www.tase.co.il/TASEEng/Homepage.htm) that included its strategic plan (the 2000 and 2004 updates, both in Hebrew), as well as other publications.

The information systems life cycle model (Ahituv et al., 1994), presented in Figure 2, served as the analysis framework. The questions addressed the various phases of TACT's life cycle, beginning with its initiation, through its implementation and current operation. The content validity of the structured interview questions and the mail survey has been established first by a thorough literature review, and then by a pilot. The pilot included in-depth interviews with three senior experts, who had the relevant academic, business and information systems knowledge, as well as profound acquaintance with TASE and its major members.

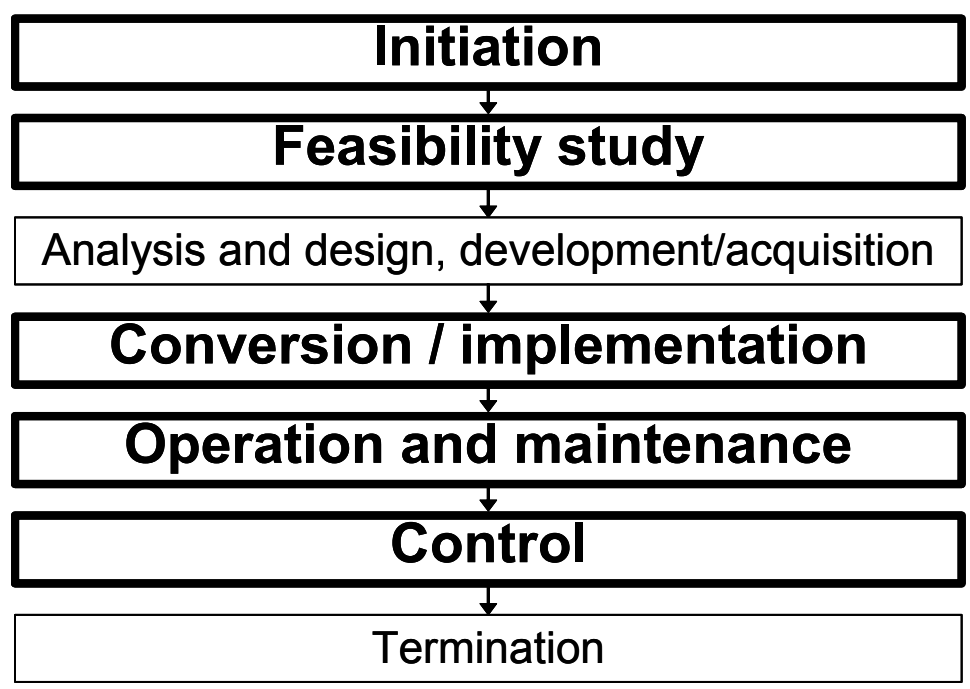

Legend: Emphasized stages are included in the study

Figure 2: Analysis framework: The information systems life cycle model

The quantitative data was analyzed with SPSS, and due to the small sample, nonparametric tests were mainly used. The high response rate of the mail survey, $64.5 \%$, indicates adequate external validity with regard to the TASE members' population. In addition, non-response bias was checked by comparing the responses for the quantitative items of the survey by early respondents and late respondents (Armstrong \& Overton, 1977). The results of the Kruskal-Wallis test showed no significant difference. Hence, it indicates that the sample represents the research population.

\section{Tel-Aviv Stock Exchange and Its Trading Systems}

The Tel Aviv Stock Exchange was established in 1953, as a private company limited by guarantee. TASE is owned by its members, which include most of Israel's banks and its main investment 
houses. TASE provides investors in Israel and abroad with securities trading services and offers capital-raising services to corporations and the Israeli government. TASE structure and its activities are regulated by the Israeli Securities Law, and it is supervised by the Israel Securities Authority. In addition to its board of directors, TASE is managed by committees that are staffed by representatives of its members.

In 1996, before the inauguration of TACT, the average stock market daily turnover was 33 million USD. By 2007, it had reached the level of 505 million USD. Throughout this period between 550 to 650 companies were listed. The derivatives daily turnover during the period grew from 24 to 385 thousands of contracts (on TA 25 index - TASE 25 most traded securities).

The revenue sources of TASE include commissions, paid by its members for trading and clearing activities and commissions charged from companies that raise capital or use any of its other services. These revenues are intended to cover the costs of TASE current operations, projects, and reserves for downturns.

Up until 1997, most TASE trading was conducted in physical trading floors. The migration to TACT enabled TASE to successfully change its trading processes and to overcome threats in its business environment. Kalay, Wei, \& Wohl, (2002) provide a detailed description of the TASE trading processes before and after the implementation of TACT. The fully computerized real-time continuous trading system currently deals with all forms of securities trading, such as stocks, convertible securities, corporate and government bonds, index options and futures, currency options and futures and a variety of securities derivatives.

The major milestones of the TACT project were:

- 1994 - The board of directors instructs TASE management to examine the feasibility of establishing a computerized continuous trading system.

- 1995 - The TACT project is approved by TASE board of directors.

- 1997- "TACT stocks" inaugurated. Within one year, the trading of 977 securities were moved to TACT.

- 1998 - 'TACT bonds" inaugurated.

- 1999 - "TACT derivatives" inaugurated.

In the following years, TASE has continued the development of its systems and advanced services were added, including:

- 2001 - The inauguration of MAYA, a disclosures website that publishes announcements from listed companies, as well as from TASE.

- 2002 - The inauguration of Galaxy, providing global clearing, settlement and custody services for securities traded in the United States in collaboration with Citigroup.

- 2006 - A new website, providing a constant flow of data on trade, as well as reviews, research and general information about trade and the capital market.

The following three sections analyze the implementation of TACT. The next section uses the extended IOS feasibility model to examine TACT's initiation and to identify the major constraint of its implementation. The second section analyzes how TASE management overcame the organizational challenges that were identified as the system constraint. Finally, the impact of TACT on TASE and its members is analyzed in retrospect. 


\section{TACT's Implementation in View of the Extended IOS Feasibility Model}

This section includes a qualitative analysis of TACT according to the extended IOS feasibility model. It examines the circumstances that have led to TACT's initiation, the factors that influenced the project's feasibility, and the conditions required for successful operation of TACT by TASE and its members. The analysis below shows that all the factors included in the extended IOS feasibility model had indicated, ex-ante, the high feasibility of TACT and identifies the factor organizational infeasibility as the constraint of TACT's implementation. The analysis is based on interviews with 10 senior executives who were involved with the TACT project and on the answers to the open questions included in the 20 responses to the mail survey.

\section{Perceived Potential Benefits of IOS}

\section{TASE motivation to initiate TACT}

The main reasons for the initiation of a fully automated continuous trading system by the TelAviv Stock Exchange were as follows:

- The threat of establishment of a second stock exchange in Israel - The high tide of the stock market during the years 1992-1993 had increased the strategic threats on TASE and encouraged those who were interested in establishing a second stock exchange in Israel, which would focus on high-tech firms, NASDAQ style. It was obvious that trading would be automated and continuous, thus it would have drawn most trades to the new stock exchange. Such an exchange would not be limited by the need to consider its members and it could have based its activity on off-the-shelf software, which would enable its immediate operation and, in doing so, create a substantial advantage over TASE. Therefore, implementing an automated continuous trading system that would be fully functioning before a second exchange could be established was a crucial strategic necessity for TASE. In retrospect, the implementation of TACT created such an effective entry barrier, reducing the attractiveness of a second exchange.

- The floor trading being a bottleneck - The bilateral trading of the 100 most commercial stocks, as well as the derivatives, was based on trading floors in which each security had been traded in its turn, without continuity. Trading volume was creating unacceptable backlogs in fulfilling customer orders. The trading orders were given by agents of the TASE members, and their number was limited to five agents per member. As the trading volumes increased, the trading time of each security got longer and the number of trade rounds decreased. Consequently, some of the trading orders were not executed, and it was impossible to increase TASE's trading volume. There were also other disadvantages of floor trading:

- The agents on the trading floor had an information advantage over the customers. There was inequality in customers' accessibility to information and the trading floor. As the number of customers of a TASE member was greater, their accessibility decreased (as mentioned above, each member had only five agents).

- There was limited ability of customers to react to changing situations during the trading day. Many customers could submit orders that could be executed only during the following trading day.

- The TASE unique trading method was unclear to foreign investors - Although in the years 1992-1993 there was a global trend of foreign investors entering emerging exchanges, 
just a few of them were active in TASE, mainly due to the complex discontinuous trading method.

In summary, TACT was expected to prevent a major strategic threat of a second exchange, to enable TASE to increase the trading volume in response to market demand, to reduce trading leadtime, and to improve customer service. The transactional potential benefits were not enough to serve as an incentive for the TACT project. These benefits, such as reduced costs and fewer errors, were evident for years before the TACT initiative. The London Stock Exchange had been fully automatic since 1986, and the financial sector in Israel already used many computerized systems at that time. Still, until the need for change became crucial, the old processes prevailed.

\section{The members motivation to support the TACT initiative}

From the members' point of view, TACT was supposed to serve all of them; hence, its ability to create a strategic advantage for a single member was limited. Nevertheless, TACT had potential to increase the overall revenues of the members from securities trading. As further discussed below, TASE, as an objective intermediary, had a power position over the small members. The largest banks supported the project for two main reasons: First, global trends and the well-being of the Israeli capital market had made the change unavoidable. Second, TACT answered a major business need of the members. The main purpose of TACT was to increase the trading volume. The old method had limited the ability to serve the investors, and it was costly and inefficient. This was especially true for the big banks that had to serve a large number of customers.

\section{Interaction Characteristics}

The main interaction characteristics suggested in this study to have influence on IOS feasibility are frequency, lead-time, structural complexity, and relationships intensity.

Frequency. TASE handles thousands of trading orders per day. The activity in each of the member organizations could be dozens, hundreds, thousands and even many more transactions per day. As a member organization handled more trading orders, its incentive to computerize the process increased. Moreover, automation enables a dramatic increase in the number of carried out transactions, which usually means higher commission revenues.

Lead-time. Before the inauguration of TACT, the time between the issuance of the trading order by the customer and its fulfillment could be a few minutes, hours or a few days, depending on the customer type and the nature of the transaction. Customers value fast response, since it is usually expected to yield them higher profits or to reduce their losses. TACT had enabled a much faster lead-time for virtually all the customers.

Structural complexity. The transactions are well defined and programmable. Structural complexity is low and this encourages automation.

Relationships intensity. In this case, relationships intensity is high:

- The activities are carried out with the same partners.

- High availability is required to attend to members' requests.

- Members need to share data in order to serve their customers.

- Communication is required to retain and update securities ownership data.

Overall, the interaction characteristics encourage automation. However, as mentioned earlier, most of these benefits (excluding the ability to increase revenues by handling more transactions), are considered to be operational benefits, and usually they are not enough to motivate IOS im- 
plementation, especially if the project is complex and requires considerable top management attention.

\section{Power Position of an Initiator}

TASE, the initiator of TACT, apparently had no power position over its five biggest members. The smaller members had no choice; they had to adapt themselves to TASE's decisions, since their alternative was not to continue their trading activities. Nevertheless, even a big bank could not object once the decision had been made, because if that member was not ready on the agreed upon date to operate TACT, it would have found itself at a disadvantage versus its competitors. Only if a few big members were not ready could the inauguration have been postponed. An individual major member would not necessarily know the readiness status of other members. Hence, they all made the necessary efforts to be fully prepared as requested.

\section{Maximal Infeasibility}

Maximal infeasibility is the highest among the values of five factors: economic infeasibility, organizational infeasibility, technological infeasibility, risks, and lack of financial resources.

Economic infeasibility. Although cost/benefit analysis had been limited to general estimations, all the partners felt that TACT would be a profitable project. In retrospect, as further discussed below, TACT was considered worthwhile.

Organizational infeasibility. Although TASE, as an objective intermediary, held a power position over the members, they could have still withheld the project. There were many joint decisions; achieving a consensus was necessary. Since this factor is the most challenging one, it was identified as the system constraint, and the next section describes how TASE management has handled this challenge.

Technological infeasibility. The necessary technologies were available but TASE lacked experience and expertise with their deployment. Therefore, it was decided to use outsourcing. Ex-post, it turned out that the supplier had not possessed all the required abilities. For example, the communication structure that was supposed to be under the responsibility of the supplier was finally designed and built by TASE with the assistance of external communication companies. However, ex-ante, technology issues were not expected to constrain the project; the banks had the required infrastructure and the investment houses were using outsourcing services that could handle the move to TACT.

Risks. All the parties involved in the project had extensive experience with handling sensitive information, so TACT had not posed any new challenges in this area. TASE, as an objective intermediary, had virtually eliminated the risks of opportunistic behavior. Nonetheless, some of the decisions that were made in order to ensure a fair play, such as the decision that all the members will migrate to the new system at the same time, increased the project's complexity.

Lack of financial resources. The direct cost of the project for TASE was about 5 million USD, an investment that was well within the capability of TASE members.

In conclusion, ex-ante there were no indications of economic infeasibility, technological infeasibility, security or opportunistic risks, and there were adequate financial resources. The sole factor that could have mostly jeopardized TACT's implementation was, therefore, organizational infeasibility.

\section{Control Variables: Organization Size and Industry IOS Status}

Organization size. There are two common measures of organization size: sales/turnover and number of employees (Lee \& Xia, 2006). The daily trading volume at TASE before TACT's ini- 
tiation was beyond 100 million USD. Sometimes, it was much lower, due to downturns, but still the transaction volume was tens of millions of USD. The number of employees in the member organizations was as few as 15 and as many as over 10,000. Overall, the large volume of activities and the size of the main organizations involved in the TACT project supported its feasibility.

Industry IOS status. TASE is the only stock exchange operating in Israel. However, at that time, there were some electronic exchanges abroad, such as the London Stock Exchange (Clemons \& Weber, 1990). The Israeli banks were deploying many IOS, such as SWIFT for international inter-bank messages. Therefore, the industry IOS status had enhanced TACT's feasibility.

\section{Analysis Conclusion}

The results of the above analysis demonstrate the extended IOS feasibility model applicability to IOS that are shared by competitors, as well as for analyzing the feasibility of a system. Virtually, all the model's factors predicted TACT's success. Organizational infeasibility has been identified as the weakest link, i.e., the constraint, which might have delayed the implementation or even prevented it.

\section{Elevating the Organizational Feasibility Constraint}

The fruitful cooperation between the TASE members had a crucial influence on TACT's successful implementation. Although there has been a long-lasting prior cooperation between the banks in operational functions, such as automatic teller machine (ATM) services to their customers, the TACT project required a much stronger level of cooperation. Unlike other joint systems, in which every organization could set its own schedule for connecting to the system and select the connection type, the TACT project required a simultaneous transfer of all TASE members to the new system. This meant that each member had to complete its internal lineup and communication interface with TASE, including all the necessary checks, training, procedures, and so forth, and all members had to start the acceptance tests simultaneously at the agreed upon date. A delay by a few members might have delayed the whole project. The close cooperation was needed especially among the largest banks, whereas the other members coordinated mainly with TASE. This section analyzes the main factors that enhanced the TACT project organizational feasibility.

\section{TASE as a Neutral Managing Intermediary}

TASE had a key role as a neutral, objective managing intermediary. For instance, four out of the five biggest banks had to develop an SNA (Systems Network Architecture, which is an IBM computer networking protocol) communication interface. Instead of parallel development of four similar interfaces by each bank, it was suggested that TASE would undertake the development of the interface through outsourcing. The advantages of joint development are obvious: a uniform interface with TACT, smaller development and maintenance costs, as well as shortening the leadtime for completing the acceptance tests. However, the demand of the banks that TASE would manage the SNA communication interface project was not so obvious. TASE had at that time about 80 employees in its computing unit, while each one of the involved banks had a much bigger professional information technology divisions. Eventually, TASE undertook the management of the SNA project, and this action has had a major contribution to the ability of TASE to operate flawlessly and simultaneously in all the member organizations, which was essential for the project's success.

\section{Adopting a Trading Software Along with Its Trading Method}

The transfer to continuous simultaneous trading involved changes to the securities trading method. TASE decided to acquire a proven system that had already been operating elsewhere 
(among others, the chosen system was implemented by the Chicago Stock Exchange) and that naturally operated according to well-defined acceptable trading rules. This way, it was much faster and easier to reach an agreement regarding the trading method, as opposed to in-house development, which would potentially open endless trading rules alternatives-deliberations that would have been lengthy, and might have postponed the whole project. As already mentioned, the timing element was critical.

\section{Establishing a Computerization Committee}

TASE board of directors had established a computerization committee that was headed by a senior executive of one of the largest banks. Its members included the CIOs of the four major banks, as well as a representative of the investment houses. The chairperson of the TASE trading committee, the TASE chairperson of the board of directors, the TASE CEO, and the TASE CIO, along with her deputy, were also present at all committee meetings. This is noteworthy, since sometimes the committee convened twice a week. All the interviewees emphasized the role of the computerization committee, as a mechanism for cooperation and control, in contributing to the TACT project success.

\section{Top Management Determination, Commitment and Involvement}

Participation in the computerization committee meetings, as described above, was just one aspect of the deep commitment of TASE top management to the TACT project. During those meetings, the business executives stressed the importance of a fast action and prevented schedule delays. Since the timely success of the TACT project was considered a strategic imperative, this involvement may seem natural. Notwithstanding, in many cases information systems projects fail due to lack of top management attention and involvement. Hence, such involvement should not be taken for granted.

\section{Careful Planning of the Conversion}

Much thought and effort were given to planning the conversion process, since this was a major risk, and in case of technical failure, there might not have been a second chance to launch the system. The project was divided to three major stages: "TACT stocks", "TACT bonds", and "TACT derivatives". The first system to be launched was "TACT stocks". Since the stock trading process does not allow parallel conversion (i.e., the same security is traded in the physical trading floor and in the new TACT system), a crash conversion was imperative. However, a crash conversion of all the nearly 1,000 traded stocks seemed too risky. Therefore, a gradual conversion process was planned; once a particular stock was moved to TACT, it would be traded only through the TACT system.

The first phase included the 10 most traded stocks that were not included in the TA25 index (i.e., TASE 25 most traded securities). It was considered too risky to choose stocks that might influence the TA25 index; on the other hand, it was important to choose stocks that would invariably be traded. As a result, there were transactions during the first days of the conversion that permitted the system to be examined in real trading situations. Although many large-scale simulations had been performed prior to launching, there was also the human element and external events in the business environment, such as a sudden notice of some crisis that might have influenced real performance.

On August 14, 1997, the first 10 stocks were moved to TACT, and the system operated successfully. By December 31, 1997, all the 100 most traded securities were moved to TACT, in small lots of about 15 stocks at a time, every two or three weeks. Shortly afterwards, the nearly 900 less traded stocks were also transferred. Kalay et al. (2002) provide a detailed account of the transfer 
process, and their research indicates that during the conversion phase, those stocks that were moved to TACT had greater trading volumes.

The gradual conversion was very convenient for the members and their employees, who during the first few weeks learned how to cope with continuous simultaneous trading of a few securities. The challenges encountered were not technical nor were they due to changes in working procedures. Instead, most difficulties resulted from the need to make investment decisions in a new, different business environment; one that is extremely dynamic (as opposed to the physical floor trading), and operates under new rules.

\section{TASE Support of the Smaller Members Project Control}

Some of the smaller TASE members needed help in controlling the outsourcing contractors, retained to help them develop the necessary internal systems. TASE handled the project control for these members, and by this action, it also ensured that they were ready in time for TACT's inauguration. TASE has also supported the conversion process and assisted in employee training.

\section{Business Users Cooperation within the Member Organizations}

Beyond the technical aspects of connecting to the TASE computer, to reap benefits from the transition to TACT, the members were required to adapt existing systems or develop and implement internal information systems, as well as systems intended for their customers. For example, such systems would enable customers to issue trading orders automatically for immediate execution and provide them with online access to trading data. Nowadays, there are many websites of financial companies that provide similar services, but it was not so at the time of TACT's inauguration. The members had to use their own systems because these systems were intended for their customers and, at the time, they believed that the systems would provide them with competitive advantages, even though it may not be sustained. The cooperation of the business users (i.e., security trading division managers of the banks, portfolio managers in investment houses) within the members' organizations was very important for the success of the internal systems; however, their involvement was not needed in the activities concerning the implementation of TACT by TASE.

\section{TACT's Impact on TASE and Its Members in Retrospect}

From the perspective of TASE, TACT has achieved all its intended purposes:

- Ten years later, a second stock exchange has not been established in Israel. Even if such an exchange operates sometime in the future, the strategic threat on TASE has been considerably reduced.

- TACT has created a technological infrastructure that enables global connectivity and fulfillment of TASE business strategy.

- The reduction of the trading commissions that TASE charges its members is a quantitative indicator of TACT's economic worthiness. During the period 1994-1999, the commission rates were fixed. In 2000, the commissions on stock and derivatives trading were reduced. Nevertheless, the derivatives trading commissions became TASE's largest source of revenues.

Table 1 presents major indicators of the TASE activities during the years 1993-2008. The year 1997, when "TACT stocks" was inaugurated is emphasized and so is 1999, the time of the "TACT derivatives" launch. If one considers the stock trading volume level in the high-tide years 1993-1994 as the maximal trading capacity of the physical trading floors, then TACT has enabled a major elevation of the constraint, e.g., an average daily turnover of 505 million USD in 2007 versus 123 million USD in 1993. The increase in the derivatives market is even more dramatic, as 
can be seen in Table 1. Another evident trend is the decrease in the market share of the banks. There are many reasons for this phenomenon, such as regulation, which are beyond the scope of this study.

The main benefits of TACT from the members' perspective, as indicated in the interviews and the mail survey responses, are:

- Faster accessibility to the trading floor.

- Ability to increase trading volume (of each member).

- Real-time monitoring on performance and instant reporting to customers.

- Improved control over customer transactions.

- Cost savings and efficiency.

- Transparency of information, equality, anonymity (i.e., the identities of the traders are not revealed).

\begin{tabular}{|c|c|c|c|c|c|c|}
\hline \multicolumn{7}{|c|}{ Table 1. TASE stock market and derivatives activity $1993-2008^{*}$} \\
\hline \multirow[t]{2}{*}{ Year } & \multirow{2}{*}{$\begin{array}{c}\begin{array}{c}\text { Stock market } \\
\text { daily } \\
\text { turnover }\end{array} \\
\text { (US\$ millions) }\end{array}$} & \multirow{2}{*}{$\begin{array}{c}\text { Total } \\
\text { listed } \\
\text { companies }\end{array}$} & \multirow{2}{*}{$\begin{array}{c}\text { Derivatives } \\
\text { daily turnover } \\
\text { (TA25 } \\
\text { thousands of } \\
\text { contracts) }\end{array}$} & \multicolumn{3}{|c|}{$\begin{array}{c}\text { Distribution of stock trade } \\
\%\end{array}$} \\
\hline & & & & $\begin{array}{l}5 \text { banks } \\
\text { groups }\end{array}$ & $\begin{array}{l}\text { Other } \\
\text { banks }\end{array}$ & $\begin{array}{c}\text { Other } \\
\text { members }\end{array}$ \\
\hline 1993 & 123 & 558 & 3 & 73.2 & 9.7 & 17.1 \\
\hline 1994 & 104 & 638 & 18 & 72.6 & 12.3 & 15.1 \\
\hline 1995 & 37 & 654 & 23 & 67.2 & 14.3 & 18.5 \\
\hline 1996 & 33 & 655 & 24 & 63.8 & 15.4 & 20.8 \\
\hline 1997 & 59 & 659 & 24 & 59.6 & 15.0 & 25.4 \\
\hline 1998 & 62 & 662 & 31 & 53.5 & 13.4 & 33.1 \\
\hline 1999 & 86 & 654 & 45 & 57.5 & 12.7 & 29.8 \\
\hline 2000 & 115 & 665 & 108 & 53.4 & 14.1 & 32.5 \\
\hline 2001 & 64 & 649 & 110 & 47.6 & 14.1 & 38.3 \\
\hline 2002 & 51 & 624 & 118 & 49.8 & 14.9 & 35.3 \\
\hline 2003 & 80 & 577 & 120 & 53.6 & 10.4 & 36.0 \\
\hline 2004 & 147 & 578 & 153 & 57.2 & 9.9 & 32.9 \\
\hline $\begin{array}{c}2005 \\
* *\end{array}$ & 223 & 584 & 258 & 65.0 & NA & 35.0 \\
\hline $\begin{array}{l}2006 \\
* * *\end{array}$ & 326 & 606 & 305 & 59.2 & NA & 40.8 \\
\hline 2007 & 505 & 654 & 385 & 56.0 & NA & 44.0 \\
\hline 2008 & 547 & 642 & 332 & 56.4 & NA & 43.6 \\
\hline
\end{tabular}

* Data source: reports available at the TASE website www.tase.co.il

** As of 2005, the data regarding the other banks are not reported due to their insignificant share, and they are included in the five banks groups figures.

*** As of 2006, due to regulation, the banks had to sell some of their activities, so it influenced their trade share.

Analysis of TACT's economic impact on the members, drawn on data from the mail surveys, indicates that the six participating banks reported medium and high levels of labor savings, while the 14 investment houses reported minor savings or no reduction at all. A Kruskal-Wallis test showed that these differences were significant. Apparently, it is hard to save labor costs when an 
investment house has about 15 employees whose time is mainly dedicated to investment decisions and control. However, a bank with thousands of employees and hundreds of thousands of customers has many more opportunities to improve its processes.

TACT reduced customer lock-in, meaning that it enabled customers to easily switch their trading service provider. The customers no longer needed personal interaction (such as a phone conversation) with the broker to ensure that their trading orders would be fulfilled. Thanks to the automatic trading processes, each member could virtually handle all the customers that required its services. Before the implementation, some of the members, especially the investment houses, could not fulfill all their customers' requests for trading services due to the need for human interaction, and it limited their ability to acquire new customers. After the implementation, the members had excess capacity, so they tried to get more customers. Thus, TACT's implementation has caused a reduction in the commission rate that the members charge their customers. This reduction was stronger in the banks ( 3.80 on a 1-5 point Likert scale) than in the investment houses (2.86). This indicates that TACT had increased customer bargaining power against the members. It does not necessarily mean that the members' revenues decreased, since the trading volume increased.

TACT has created a need for ongoing investments by the members in improving their technical infrastructure. This issue has been indicated as a critical success factor of the system operation in the member organizations and the major challenge that the members face. The average score of the answer to the question "to what extent has the TACT implementation forced your organization to continuously invest in information and communication infrastructure in order to keep a competitive service level?", was 4.32 out of 5 (standard deviation $0.749, \mathrm{n}=20$ ). There was no significant difference between banks and investment houses. Nevertheless, the members have considered TACT as cost/benefit effective for their organization. The score for banks was 4.50 and for investment houses 3.85 .

It is not common that a CIO becomes a CEO (Cappelli \& Hamori, 2005). In 2006, Ester Levanon, who since 1986 had served as TASE CIO, and later became the Executive Vice President as well, was appointed TASE CEO. Ester Levanon has led the revolution of computerizing the trading and clearing processes. The main projects that were carried out under her leadership were the transition to TACT for all types of securities, the establishment of a fully computerized clearing system, and the establishment of advanced systems to manage risk in the derivatives market and at the Clearing House. In retrospect, this also indicates the success of the TACT project.

\section{Discussion}

\section{Theoretical Implications, Limitations and Further Research}

This study has extended the IOS feasibility model of Geri \& Ahituv (2008) by adding the interaction characteristics construct to the factors that influence IOS implementation and demonstrating how it can be applied in the context of a single IOS that is shared by competitors. In doing so, the study illustrated how the Theory of Constraints (Goldratt \& Cox, 1986, Ronen \& Pass, 2007) can be employed in such situations.

One may question the generalizability of the findings of this study, which concerned Israeli organizations. Banks and investment houses, as well as most of the large and medium firms in Israel, conduct extensive international relationships with customers, suppliers, and partners, and sometimes their ownership is held by international companies. Furthermore, the information and communications technological infrastructure in Israel is equivalent to those prevailing in other developed countries. Hence, this suggests that the findings of this study may be generalized to global firms. According to Markus and Soh (2002), e-commerce activities depend on the local 
structural conditions that may vary between countries and locations. These conditions include geographic structure, which influences distribution of goods, communications infrastructure and its costs, and financial arrangements regarding payments and credit. Therefore, the findings may be applicable to systems that operate under similar structural conditions. However, since the main constraint that this study has dealt with was organizational infeasibility, and these issues are culture related, it may be worthwhile to carry out a comparative study within the same industry (i.e., banking and finance) in other countries, or in other industries.

This study examined a mandated IOS, so some of the findings may not be applicable to voluntary IOS. Nevertheless, the members of the IOS described in this paper could have prevented its establishment. Similarly, major organizations have critical influence on the establishment of "voluntary" industry IOS, such as ORBITZ in the airline industry. Once such IOS are successfully established, organizations are virtually compelled to join them in order to facilitate their operations. The dynamics of establishing a successful voluntary IOS require further research.

The longitudinal analysis, which referred to events that happened between 1993 and 2008, has enabled a wider perspective of the strategic implications of TACT's implementation. The interviews and mail survey took place in 2000-2001, about two years after the full implementation of TACT. Nowadays, TACT is regarded as an ordinary element of the stock exchange; therefore, it would not be feasible to conduct a follow-up study among TASE members. However, it is important to examine the extended IOS feasibility model in the context of other IOS, in order to substantiate its validity.

Another important research direction is to integrate the concepts of IOS and fulfilling the information needs of its participating organizations within the framework of informing science (Cohen, 1999; Gill \& Bhattacherjee, 2007; Gill \& Cohen, 2009). Table 2 depicts the informing environment of TACT, and relates to its three levels (Cohen, 1999):

- Design - designing the system by TASE management.

- Construction - constructing the system by TASE information technology department, external subcontractors, TASE members' information technology departments and their subcontractors.

- Informing instance - i.e., using the system. In this case, there are two sub-levels, or hierarchies, of informing instances. The higher one refers to the information flow between TASE and its members. The trading orders of the members' customers are transmitted to TASE; TACT automatically performs the trade and returns the relevant information to the members. The lower sub-level refers to the members' systems that connect them to their customers, and are used to transmit trading orders, order fulfillment information, and trading data.

Cohen (2009) points the need for channel-focused research and indicates that senders and clients of information can both be collections of agents, such as the situation of TASE members described in this paper. Specifically, this paper demonstrated the challenges of an IOS, which is shared by competitors. It highlighted the role of an intermediary in forming an effective information system. The promising attributes that were explored included objectivity of the intermediary, fairness and transparency of the system, and anonymity of the clients. However, further research is required in order to form a comprehensive theoretical model within the informing science framework. 


\begin{tabular}{|c|c|c|c|}
\hline \multicolumn{4}{|c|}{ Table 2. The informing environment of TACT } \\
\hline Level & \multicolumn{3}{|c|}{ Participants } \\
\hline Design & \multicolumn{3}{|c|}{$\begin{array}{l}\text { - TASE board of directors and TASE management } \\
\text { - TASE computerization committee (a sub-committee of the board of } \\
\text { directors), headed by a senior executive of one of the largest banks. } \\
\text { Its members included the CIOs of the four major banks and a repre- } \\
\text { sentative of the investment houses. The chairperson of the TASE } \\
\text { trading committee, the TASE chairperson of the board of directors, } \\
\text { the TASE CEO, and the TASE CIO, along with her deputy, were } \\
\text { present at all meetings }\end{array}$} \\
\hline Construction & \multicolumn{3}{|c|}{$\begin{array}{l}\text { - TASE information technology department } \\
\text { - TASE external subcontractors (e.g., the vendor of the trading sys- } \\
\text { tem, the computer communication experts) } \\
\text { - TASE members' information technology departments and their sub- } \\
\text { contractors }\end{array}$} \\
\hline & Sender & Channel & Client \\
\hline \multirow[t]{3}{*}{$\begin{array}{l}\text { Informing Instance } \\
\text { (to TASE member) }\end{array}$} & $\begin{array}{l}\text { TASE member, } \\
\text { e.g. a bank, an in- } \\
\text { vestment house } \\
\text { (sends trading or- } \\
\text { der request) }\end{array}$ & \multirow{3}{*}{$\begin{array}{c}\text { TACT } \\
\text { communication } \\
\text { system }\end{array}$} & 1. TACT \\
\hline & $\begin{array}{l}\text { 2. TACT (order ful- } \\
\text { fillment informa- } \\
\text { tion) }\end{array}$ & & 2. TASE member \\
\hline & $\begin{array}{l}\text { 3. } \\
\text { trading (general } \\
\text { rates and vol- e.g. } \\
\text { umes) } \\
\end{array}$ & & 3. TASE member \\
\hline \multirow[t]{3}{*}{$\begin{array}{l}\text { Informing Instance } \\
\text { (to customer of } \\
\text { TASE member) }\end{array}$} & $\begin{array}{l}\text { A. A customer of a } \\
\text { member, i.e., an } \\
\text { investor (sends } \\
\text { trading order re- } \\
\text { quest) }\end{array}$ & \multirow[t]{3}{*}{$\begin{array}{l}\text { Members' systems } \\
\text { (proprietary and } \\
\text { others) } \\
\text { Personal interac- } \\
\text { tion (phone, fax, } \\
\text { e-mail, face-to- } \\
\text { face) }\end{array}$} & $\begin{array}{l}\text { 1. TASE member } \\
\text { (information is } \\
\text { conveyed to the } \\
\text { system that is } \\
\text { connected to } \\
\text { TACT) }\end{array}$ \\
\hline & $\begin{array}{ll}\text { 2. } & \text { TASE member } \\
\text { (order fulfillment } \\
\text { information) }\end{array}$ & & $\begin{array}{l}\text { 2. A customer of a } \\
\text { member (i.e., an } \\
\text { investor, an indi- } \\
\text { vidual consumer } \\
\text { or organization) }\end{array}$ \\
\hline & $\begin{array}{l}\text { 3. TASE member } \\
\text { (general trading } \\
\text { data, e.g. rates and } \\
\text { volumes) }\end{array}$ & & $\begin{array}{l}\text { 3. A customer of a } \\
\text { member (i.e., an } \\
\text { investor, an indi- } \\
\text { vidual consumer } \\
\text { or organization) }\end{array}$ \\
\hline
\end{tabular}

\section{Practical Implications}

This study has used a qualitative case methodology, which as suggested by Gill \& Bhattacherjee (2009) increases its relevance for external practitioner clients. The main practical implication emanating from this study is the importance of a neutral intermediary in the formation of an IOS 
that is to be shared by competitors. As part of managing the IOS project, this intermediary has to ensure fairness of the system and to disallow opportunism by any of the IOS participants.

The major critical success factor of TACT was information systems management skills. There was no one "big" decision, but there were many "small" decisions along the project's span and each one of them had a significant impact on TACT's success, e.g., the decision that the identities of the traders will be kept anonymous. Before TACT, the members' representative on the physical trading floor saw which member was buying and who was selling a certain stock, and this knowledge affected the trading patterns. While designing TACT, it was decided not to include the buyers and sellers identities in the reports to the members. The interviewees that referred to this decision indicated that the anonymity of the traders enhanced trading volumes and increased the system's fairness. Excellent management skills are hard to find and imitate, therefore, as Mata et al. (1995) suggest, possessing this expertise may provide an organization with competitive advantage.

The following critical success factors of TACT, as suggested by the managers who were interviewed in this study, may help organizations in implementing IOS. These guidelines are applicable to the intermediary organization, which manages the IOS project and its operation, as well as to the IOS participants.

- Applying an IOS to support main or critical business needs of the participants.

- Cooperation between the participants that is based on actions that support their business interests.

- Having a neutral intermediary and establishing mechanisms for management, cooperation and control.

- Determination, commitment and involvement of top management.

- Careful planning of the conversion stage, including support of "small" partners and providing employees with appropriate training and guidance.

- Adoption of conventional communication standards.

- Integration with relevant internal information systems.

- Ensuring an adequate level of reliable infrastructures, response time and system stability.

- Thorough experiments prior to operation, including extremely irregular heavy loads.

- The quality of the system: simple and user friendly.

- Choosing a system that is based on generally accepted trading processes.

- Being sensitive to the market needs, implementing necessary changes, as well as adaptation of working processes.

- Establishment of monitoring and control procedures and their enforcement.

\section{Conclusion}

This paper examined an extended version of the IOS feasibility model (Geri \& Ahituv, 2008), which is based on the Theory of Constraints (Goldratt \& Cox, 1986), in the context of an IOS that is shared by competitors. The analysis of the TACT implementation by TASE and its members supported the model. It explained why the members endorsed the TACT initiative, even though it undermined their competitive position and strengthened the investors. This research emphasized the importance of a neutral intermediary that manages the IOS and suggested that the main criti- 
cal success factor is information systems management skills. These skills enabled TASE management to overcome the organizational issues, which were the constraint of TACT's development and implementation. The establishment of TACT was a critical strategic necessity for TASE, which as a neutral intermediary had a power position over its members that could not object to such a move.

Reflecting on the transition to TACT, a CEO of a major Israeli investment house concludes: "TACT enables each and every person an immediate access to the virtual trading floor. The former physical trading floors, based on human auctioneers and member representatives who shout trading orders, did not enable real time response; a member could not serve all its customers; nobody saw what really happened during the trade. Nowadays, everybody sees the same information at the same time. TACT has dramatically changed the market: accessibility, availability, transparency, fairness, everything is much better, on a major scale. Nevertheless, the real beneficiaries are the customers, i.e., the investors, and not TASE members. The commissions have been significantly reduced since the technology is available to everyone. The competition requires major investments in information technology infrastructure, such as new hardware and communication lines, to improve response time to customer orders in a few seconds in order to have a relative advantage over other members in accessing the trading system. Before TACT was established, customers were dependent on a representative, which only big customers could afford. Nowadays, there is no discrimination, every customer has direct access to the virtual trading floor, and all the advantages were transferred to the customers".

\section{References}

Ahituv, N., Neumann, S., \& Riley, H. N. (1994). Principles of information systems for management (4th ed.). Dubuque, IA: Wm C. Brown Communications, Inc.

Armstrong, J. S., \& Overton, T. S. (1977). Estimating nonresponse bias in mail surveys. Journal of Marketing Research, 14(August), 396-402.

Arrow, K. J. (1963). Social choice and individual values (2nd ed.). New York: John Wiley and Sons.

Borman, M. (2006). Developing, and testing, a theoretical framework for inter-organisational systems (IOS) as infrastructure to aid future IOS design. Information Systems and E-Business Management, 4(4), 343-360.

Cappelli, P., \& Hamori, M. (2005). The new road to the top. Harvard Business Review, 83(1), 25-32.

Chwelos, P., Benbasat, I., \& Dexter, A. S. (2001). Research report: Empirical test of an EDI adoption model. Information Systems Research, 12(3), 304-321.

Clemons, E. K., \& Weber, B. W. (1990). London's big bang: A case study of information technology, competitive impact, and organizational change. Journal of Management Information Systems, 6(4), 41-60.

Coase, R. H. (1937). The nature of the firm. Economica, 4, 386-495. Reprinted in O. E. Williamson \& S. G. Winter (Eds.). (1993). The nature of the firm: Origins, evolution and development (pp.18-33). New York, NY: Oxford University Press.

Coase, R. H. (1991). The institutional structure of production. Alfred Nobel Memorial Prize Lecture in Economic Sciences. Reprinted in O. E. Williamson \& S. G. Winter (Eds.). (1993). The nature of the firm: Origins, evolution and development (pp. 227-235). New York, NY: Oxford University Press.

Cohen, E. (1999). Reconceptualizing information systems as a field of the transdiscipline informing science: From ugly duckling to swan, Journal of Computing and Information Technology, 7(3), 213-219.

Cohen, E. (2009). A philosophy of informing science. Informing Science: the International Journal of an Emerging Transdiscipline, 12, 1-15. Retrieved from http://inform.nu/Articles/Vol12/ISJv12p001015Cohen399.pdf 
Crook, C. W., \& Kumar, R. L. (1998). Electronic data interchange: A multi-industry investigation using grounded theory. Information and Management, 34(20), 75-89.

Damanpour, F. (1991). Organizational innovation: A meta-analysis of effects of determinants and moderators. Academy of Management Journal, 34(3), 555-590.

DiMaggio, P. J., \& Powell, W. W. (1983). The iron cage revisited: Institutional isomorphism and collective rationality in organizational fields. American Sociological Review, 48(2), 147-160.

Geri, N., \& Ahituv, N. (2008). A Theory of Constraints approach to interorganizational systems implementation. Information Systems and e-Business Management, 6(4), 341-360.

Geri, N., \& Ronen, B. (2005). Relevance lost: The rise and fall of activity-based costing. Human Systems Management, 24(2), 133-144.

Gill, T. G. (2008). Structural complexity and effective informing. Informing Science: the International Journal of an Emerging Transdiscipline, 11, 253-279. Retrieved from http://inform.nu/Articles/Vol11/ISJv11p253-279Gill223.pdf

Gill, T. G., \& Bhattacherjee, A. (2007). The informing sciences at a crossroads: The role of the client". Informing Science: the International Journal of an Emerging Transdiscipline, 10, 17-39. Retrieved from http://inform.nu/Articles/Vol10/ISJv10p017-039Gill317.pdf

Gill, T. G., \& Bhattacherjee, A. (2009). Whom are we informing? Issues and recommendations for MIS research from an informing science perspective. MIS Quarterly, 33(2), 217-235.

Gill, T. G., \& Cohen, E. (Eds.). (2009). Foundations of informing science: 1999-2008. Santa Rosa, CA: Informing Sciences Press.

Gill, T. G., \& Hicks, R. (2006). Task complexity and informing science: A synthesis. Informing Science: the International Journal of an Emerging Transdiscipline, 9, 1-30. Retrieved from http://inform.nu/Articles/Vol9/v9p001-030Gill46.pdf

Goldratt, E. M. (1991). The haystack syndrome. Great Barrington, MA: North River Press.

Goldratt, E. M., \& Cox, J. (1986). The goal: A process of ongoing improvement. Croton-on-Hudson, NY: North River Press.

Goldratt, R., \& Weiss, N. (2005). Significant enhancement of academic achievement through application of the Theory of Constraints (TOC). Human Systems Management, 24(1), 13-19.

Gordon, S. R. (2002). Information technology and ebusiness in the financial services. Journal of Information Technology Cases and Applications, 4(4), 1-3.

Granados, N. F., Gupta, A., \& Kauffman, R. J. (2007). IT-enabled transparent electronic markets: The case of the air travel industry. Information Systems and E-Business Management, 5(1), 65-91.

Gupta, M. (2003). Constraints management: Recent advances and practices. International Journal of Production Research, 41(4), 647-659.

Hart, P. J., \& Saunders, C. S. (1997). Power and trust: Critical factors in the adoption and use of electronic data interchange. Organization Science, 8(1), 23-42.

Hart, P. J., \& Saunders, C. S. (1998). Emerging electronic partnerships: Antecedents and dimensions of EDI use from the supplier's perspective. Journal of Management Information Systems, 14(4), 87-111.

Ioannou, G., \& Papadoyiannis, C. (2004). Theory of Constraints-based methodology for effective ERP implementations. International Journal of Production Research, 42(23), 4927-4954.

Kalay, A., Wei, L., \& Wohl, A. (2002). Continuous trading or call auctions: Revealed preferences of investors at the Tel Aviv stock exchange. Journal of Finance, 57(1), 523-542.

Lee. G., \& Xia, W. (2006). Organizational size and IT innovation adoption: A meta-analysis. Information and Management, 43(8), 975-985. 
Mabin, V. J., \& Balderstone, S. J. (2000). The world of the Theory of Constraints: A review of the international literature. Boca Raton, FL: St. Lucie Press.

Mabin, V. J., \& Balderstone, S. J. (2003). The performance of the Theory of Constraints methodology: Analysis and discussion of successful TOC applications. International Journal of Operations and Production Management, 23(5/6), 568-595.

Markus, M. L., \& Soh, C. (2002). Structural influences on global e-commerce activity. Journal of Global Information Management, 10(1), 5-12.

Mata, F. J., Fuerst, W. L., \& Barney, J. B. (1995). Information technology and sustained competitive advantage: A resource-based analysis. MIS Quarterly, 19(4), 487-505.

Mnookin, R. H., \& Ross, L. (1995). Introduction. In K. J. Arrow, R. H. Mnookin, L. Ross, A. Tversky \& R. B. Wilson (Eds.), Barriers to conflict resolution (pp 2-24). New York: Norton.

Premkumar, G., Ramamurthy, K., \& Crum, M. R. (1997). Determinants of EDI adoption in the transportation industry. European Journal of Information Systems, 6(2), 107-121.

Ronen, B. (Ed.). (2005). The Theory of Constraints: Practice and research. Amsterdam: IOS Press.

Ronen. B., Coman. A., \& Schragenheim, E. (2001). Peak management. International Journal of Production Research, 39(14), 3183-3193.

Ronen, B., Lieber, Z., \& Geri, N. (2007). Value focused management (VFM): Capitalizing on the potential of managerial value drivers. In Y. Shi, D. L. Olson \& A. Stam (Eds.), Advances in multiple criteria decision making and human systems management: Knowledge and wisdom (pp.149-175). Amsterdam, The Netherlands: IOS Press.

Ronen, B., \& Pass, S. (2007). Focused operations: Achieving more with existing resources. Hoboken, NJ: John Wiley and Sons.

Ronen, B., Pliskin, J. S., \& Pass, S. (2006). Focused operations management for health services organizations. San Francisco, CA: Jossey-Bass.

Ronen B, \& Spector, Y. (1992). Managing system constraints: A cost/utilization approach. International Journal of Production Research, 30(9), 2045-2061.

Rosolio, I., Ronen, B., \& Geri, N. (2008). Value enhancement in a dynamic environment - A constraint management expert system for the oil refinery industry. International Journal of Production Research, 46(16), 4349-4367.

Shapiro, C., \& Varian, H. R. (1999). Information rules, a strategic guide to the network economy. Boston, MA: Harvard Business School Press.

Shoemaker, T. E., \& Reid, R. A. (2005). Applying the TOC thinking process: A case study in the government sector. Human Systems Management, 24(1), 21-37.

Simon, H. A. (1957). Models of man: Social and rational. New York: John Wiley and Sons.

Simon, H. A. (1971). Designing organizations for an information-rich world. In M. Greenberger (Ed.), Computers, communications and the public interest (pp.40-41). Baltimore, MD: Johns Hopkins Press.

Teo, H. H., Wei, K. K., \& Benbasat, I. (2003). Predicting intention to adopt interorganizational linkages: An institutional perspective. MIS Quarterly, 27(1), 19-49.

Wang, Y. C., Chang, C. W., \& Heng, M. S. H. (2004). The levels of information technology adoption, business network, and a strategic position model for evaluating supply chain integration. Journal of Electronic Commerce Research, 5(2), 85-98.

Willcocks, L. P., \& Plant, R. (2003). How corporations e-source: From business technology projects to value networks. Information Systems Frontiers 5(2), 175-193.

Williamson, O. E. (1979). Transaction cost economics: The governance of contractual relations. Journal of Law and Economics, 22(2), 233-261. 
Williamson, O. E. (1996). The mechanisms of governance. New York, NY: Oxford University Press

Williamson, O. E., \& Winter, S. G. (Eds.). (1993). The nature of the firm: Origins, evolution and development. New York, NY: Oxford University Press.

Wise, R., \& Morrison, D. (2000). Beyond the exchange: The future of B2B. Harvard Business Review, 78(6), 86-96.

Zhu, K., Kraemer, K. L., Gurbaxani, V., \& Xu, S. (2006). Migration to open-standard interorganizational systems: Network effects, switching costs, and path dependency. MIS Quarterly, 30(3), 515-539.

Zhu, K., Kraemer, K. L, \& Xu, S. (2003). Electronic business adoption by European firms: A cross-country assessment of the facilitators and inhibitors. European Journal of Information Systems, 12(4), 251-268.

\section{Biography}

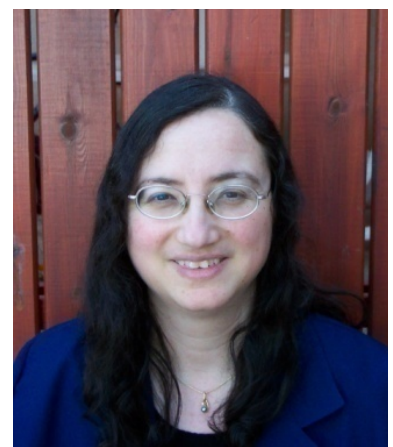

Nitza Geri is Chair of the Department of Management and Economics, the Open University of Israel, and a member of the Chais Research Center for the Integration of Technology in Education. She holds a B.A. in Accounting and Economics, an M.Sc. in Management Sciences and a Ph.D. in Technology and Information Systems Management from Tel-Aviv University. Nitza is a CPA (Israel) and prior to her academic career she had over 12 years of business experience. Her research interests and publications focus on various aspects of the value of information, and information systems adoption and implementation, including strategic information systems, e-business, value creation and the Theory of Constraints, managerial aspects of e-learning systems adoption and use. Personal site: http://www.openu.ac.il/Personal_sites/nitza-geri.html. 